\title{
Solvent-Mediated Enhancement of Additive-Controlled Crystallization
}

Ouassef Nahi, * Alexander N. Kulak, Alexander Broad, Yifei Xu, Cedrick O'Shaughnessy, Olivier J. Cayre, Sarah J. Day, Robert Darkins and Fiona C. Meldrum*

\section{Materials}

$\mathrm{CaCl}_{2} \cdot 2 \mathrm{H}_{2} \mathrm{O}, \mathrm{SrCl}_{2} \cdot 6 \mathrm{H}_{2} \mathrm{O}, \mathrm{MnCl}_{2} \cdot 4 \mathrm{H}_{2} \mathrm{O}, \mathrm{MgCl}_{2} \cdot 6 \mathrm{H}_{2} \mathrm{O},\left(\mathrm{NH}_{4}\right)_{2} \mathrm{CO}_{3}, \mathrm{NaHCO}_{3}, \mathrm{Na}_{2} \mathrm{SO}_{4}$, Brilliant Blue R (BBR), Amaranth, Fast Green, Reactive Green 19, aspartic acid and glycine, absolute methanol, ethanol, 1-propanol, 2-propanol and dioxane were purchased from Sigma Aldrich (UK). All solutions were prepared using Milli-Q deionized (DI) water. Glass slide substrates were thoroughly cleaned by soaking in Piranha solution $\left(\mathrm{H}_{2} \mathrm{SO}_{4}: \mathrm{H}_{2} \mathrm{O}_{2}-70\right.$ vol\% : 30 vol\%), washed with DI water followed by ethanol, and dried using $\mathrm{N}_{2}(\mathrm{~g})$ stream, prior to use.

\section{2. $\mathrm{CaCO}_{3}$ mineralization in the presence of soluble additives in pure water and binary solvent} mixtures

Calcium carbonate $\left(\mathrm{CaCO}_{3}\right)$ was precipitated using the ammonium carbonate diffusion method ${ }^{1}$ in the presence of the soluble additives (i.e., ions, amino acids or dye molecules) both in pure aqueous solution and in the presence of varying amount of organic co-solvents $(0-75$ vol\%). Glass substrates were deposited at the bottom of a well-plate containing a total volume of $1 \mathrm{~mL}$ of solution. Desired amounts of additives were introduced in mineralization medium containing $\left[\mathrm{Ca}^{2+}\right]=10 \mathrm{mM}-500 \mathrm{mM}$ in pure aqueous solutions or in the presence of $5-75 \mathrm{vol} \%$ of co-solvent (i.e., methanol, ethanol, 1-proparnol, 2-propanol or dioxane). Calcification in the presence of the additives was carried out by placing the reaction mixtures inside a sealed desiccator, containing $2 \mathrm{~g}$ of $\left(\mathrm{NH}_{4}\right)_{2} \mathrm{CO}_{3}$, placed in a Petri-dish covered with Parafilm punctured several times with a needle. Mineralization was allowed to proceed overnight ( $>12 \mathrm{~h}$ ). After reaction completion, the substrates supporting the crystals were washed several times with DI water and then ethanol, followed by gentle drying using $\mathrm{N}_{2}(\mathrm{~g})$ stream, prior to characterization.

3. Precipitation of $\mathrm{MnCO}_{3}$ and $\mathrm{SrSO}_{4}$ in the presence of soluble additives in pure water and binary solvent mixtures 


\section{SUPPORTING INFORMATION}

Rhodochrosite $\left(\mathrm{MnCO}_{3}\right)$ and celestine $\left(\mathrm{SrSO}_{4}\right)$ were precipitated by mixing equal volumes of $\left[\mathrm{Mn}^{2+}\right]=$ $2 \mathrm{mM}$ and $\left[\mathrm{NaHCO}_{3}\right]=200 \mathrm{mM}$ and $\left[\mathrm{Sr}^{2+}\right]=4 \mathrm{mM}$ and $\left[\mathrm{Na}_{2} \mathrm{SO}_{4}\right]=20 \mathrm{mM}$, respectively. Glass substrates were deposited at the bottom of a well-plate containing a total volume of $1 \mathrm{~mL}$ of solution. [Reactive Green] $=0.05 \mathrm{mM}$ was introduced in the $\mathrm{MnCO}_{3}$ and $\mathrm{SrSO}_{4}$ mineralization solutions in both pure aqueous solutions and in the presence of $10 \mathrm{vol} \%$ of ethanol. Mineralization was allowed to proceed overnight $(>12 \mathrm{~h})$. After reaction completions, the substrates supporting the crystals were carefully washed several times with DI water and then ethanol, followed by drying using $\mathrm{N}_{2}(\mathrm{~g})$ stream, prior to characterization.

\section{Characterization methods}

\subsection{Electron Microscopy}

Scanning Electron Microscopy (SEM) was carried out using a FEI NanoSEM Nova 450 to image the crystals grown on glass substrates. The samples were mounted on SEM stubs using carbon adhesive discs and were coated with a $4 \mathrm{~nm}$ iridium layer, prior to imaging.

Samples for Transmission Electron Microscopy (TEM) were prepared by placing a $10 \mu \mathrm{L}$ droplet of a solution of BBR (in pure water or in the presence of ethanol) on a TEM grid for 1 min. Excess solution was removed via blotting. Copper TEM grids coated with a carbon film were employed, and these were treated with a plasma glow discharge for $30 \mathrm{sec}$ to create a hydrophilic surface prior to addition of BBR solutions. A thin slice of BBR/calcite composite crystals was prepared using FIB-SEM and transferred to a copper TEM grid using a Kleindiek micromanipulator. TEM analyses were conducted using a FEI Tecnai TF20 FEGTEM with an Oxford Instruments INCA 350 EDX system/80 mm X-Max SDD detector and a Gatan Orius CCD camera operating at $200 \mathrm{kV}$.

Cryogenic Transmission Electron Microscopy (cryo-TEM) analyses of the early stages of CaCO3 mineralization in pure water and in the presence of ethanol were carried out by placing a $3 \mu \mathrm{L}$ droplets of the reaction solutions (after $\approx 30 \mathrm{~min}$ ) on Quanti-foil TEM grid that were treated with a plasma glow discharge for $40 \mathrm{sec}$ to create a hydrophilic surface. The TEM grids supporting the samples were then 


\section{SUPPORTING INFORMATION}

blotted and vitrified using an automated vitrification robot (FEI Vitrobot). CryoTEM imaging was carried out under $5 \mu \mathrm{m}$ defocus on a Thermo Fisher Scientific Titan Krios microscope equipped with a field emission gun operating at $300 \mathrm{kV}$. Images were recorded on an energy filtered Gatan K2 summit camera using a low electron dose of $5 \mathrm{e}^{-} \AA^{-2}$ per image.

\subsection{Quantification of amount of dye incorporated in calcite}

The extent of occlusion of BBR in calcite was quantified using Atomic Absorption Spectroscopy (AAS) in conjunction with UV-Vis spectrophotometry. UV-Vis spectra were recorded using a NanoDrop One/One ${ }^{\mathrm{C}}$ Microvolume UV-Vis spectrophotometer and AAS measurements were performed using a Perkin Elmer Atomic Absorption Spectrometer AAnalyst 400, operating with an air-acetylene flame. The dye/calcite composite crystals were first dissolved overnight in $5 \mathrm{~mL}$ of an aqueous solution containing $200 \mathrm{mM}$ EDTA disodium salt and $0.66 \mathrm{M}$ potassium borate buffer ( $\mathrm{pH} 10.5)$. The amount of dye released was then quantified by recording the absorbance at of the characteristic peaks of the dye molecules and comparing it to the calibration curves (absorbance vs [dye]) obtained from the EDTA buffered solutions. The extent of $\mathrm{CaCO}_{3}$ in the samples was quantified by AAS that was prior calibrated with $\mathrm{Ca}$ standard solutions. The ratios between the $[\mathrm{BBR}]$ and the $\left[\mathrm{CaCO}_{3}\right]$ contents in each sample provide the precise extents of dye incorporation within calcite.

\subsection{Thermogravimetric analysis (TGA)}

Thermogravimetric analyses (TGA) were performed from $20{ }^{\circ} \mathrm{C}$ to $850{ }^{\circ} \mathrm{C}$ in air, using a TAInstruments Q600 operating at $10{ }^{\circ} \mathrm{C} \mathrm{min}^{-1}$. The samples were bleached prior to characterization to remove the surface bound organic matter. ${ }^{2}$ Calcination of the pure calcite reference shows an onset of decomposition at $650{ }^{\circ} \mathrm{C}$, giving a weight loss of $44.0 \mathrm{wt} \%$ that is ascribed to the release of $\mathrm{CO}_{2}(\mathrm{~g})$, leaving a residue of $56.0 \mathrm{wt} \%$ that corresponds to $\mathrm{CaO}(\mathrm{s})$. The levels of incorporation of glycine (Gly) and aspartic acid (Asp) in calcite were determined by measuring the weight losses of the composites below $600{ }^{\circ} \mathrm{C}$, where these are induced by the thermal decomposition of the amino acids in the crystals. Similarly, the levels of incorporation of Reactive Green (RG) incorporated within $\mathrm{MnCO}_{3}$ and $\mathrm{SrSO}_{4}$, 


\section{SUPPORTING INFORMATION}

were determined by measuring the weight losses occurring below $300{ }^{\circ} \mathrm{C}$ for rhodochrosite (above which manganese oxide forms) and up to $900{ }^{\circ} \mathrm{C}$ for celestine. Note that the thermogram of RG alone (Figure S16) shows that $<5 \mathrm{wt} . \%$ char residues of the dye remain in the crucible, even after heating at $900{ }^{\circ} \mathrm{C}$. This shows that most of the dye decomposes at elevated temperature and that slightly higher levels of occlusion in calcite are expected. However, the $\mathrm{wt} \%$ of residual organic matter is consistent for all analyses, and the ratios of additives incorporated in the minerals in pure aqueous solutions and in the presence of various amounts of organic co-solvents are accurate.

\subsection{Synchrotron High-Resolution PXRD}

High resolution synchrotron powder XRD (HR-PXRD) measurements were performed at beamline ID22 at the European Synchrotron Radiation Facility (ESRF, Grenoble, FRANCE) and beamline I11 at Diamond Light Source (Didcot, UK). Instruments calibrations were performed using a high purity NIST SRM640c Si(111) standards. A wavelength of $0.35449587 \pm 0.00000467 \AA$ and $0.826764 \pm 0$. $000001 \AA$ were employed for the analyses of the crystals at the ESRF and Diamond Light Source beamlines, respectively. The powder samples were loaded into $0.5 \mathrm{~mm}$ borosilicate glass capillaries and the diffractograms were recorded at room temperature.

The structural parameters were refined by Rietveld refinement using PANalytical X'Pert HighScore Plus software. Lattice distortions (\%), microstrain fluctuations (\%) and coherence lengths (i.e., crystallite sizes, $\mathrm{nm}$ ) were derived from the analyses of the whole spectra and line profile analyses were performed for the (104) reflection of calcite. Goodness of fit (GOF) for all analyzed samples were $<8$, showing good quality of the fittings.

\subsection{Other measurements}

Optical micrographs of the specimens were recorded using a Nikon Eclipse LV100 polarizing microscope, equipped with both transmitted and reflected light sources. Fourier transform infrared spectra (FTIR) were acquired over the mid-infrared region $\left(600 \mathrm{~cm}^{-1}-2000 \mathrm{~cm}^{-1}\right)$ using sing a PerkinElmer ATR-IR instrument. Individual crystal polymorphs were obtained by Raman spectroscopy, using 


\section{SUPPORTING INFORMATION}

a Renishaw 2000 Raman Microscope, equipped with a $785 \mathrm{~nm}$ diode laser. Turbidimetry was used to probe the effects of the ethanol on the early stages of the $\mathrm{CaCO}_{3}$ precipitation by monitoring the light absorbed by the samples. Turbidity measurements were carried out over time using a NanoDrop One/One ${ }^{\mathrm{C}}$ Microvolume UV-Vis spectrophotometer by mixing equal volumes of $\left[\mathrm{Ca}^{2+}\right]=20 \mathrm{mM}$ and $\left[\mathrm{NaHCO}_{3}\right]=200 \mathrm{mM}$ aqueous solutions in the absence and the presence of ethanol ( $\left.5-75 \mathrm{vol} \%\right)$. The recorded absorbance measurements were converted into transmittance recovery plots using Transmittance $=10^{2-\text { Absorbance }}$. 


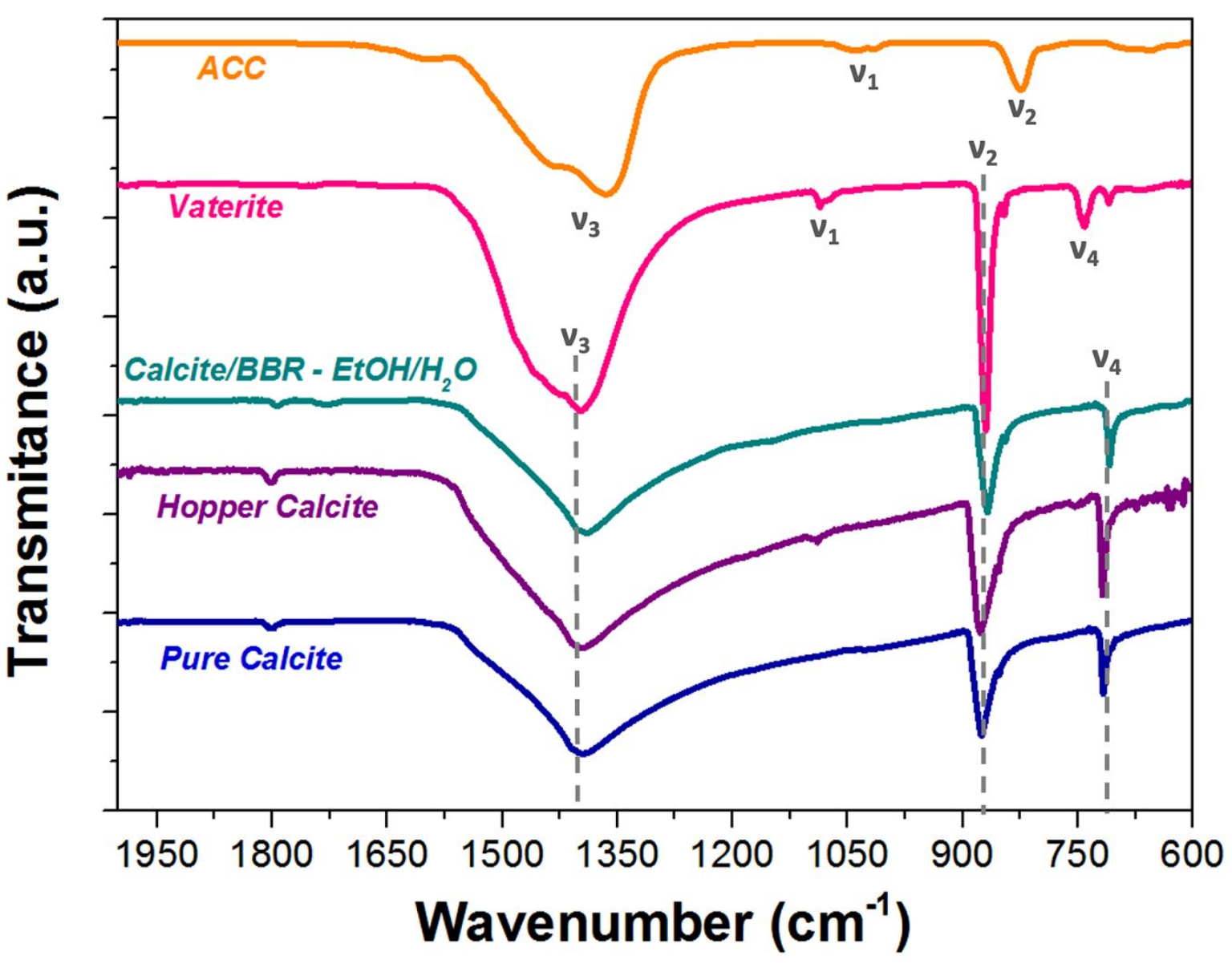

Figure S1. FTIR spectra of ACC (orange), vaterite (pink), pure calcite (blue), hopper calcite (purple) and calcite/BBR hybrid crystals grown in ethanol-water mixtures, showing the characteristic vibrational peaks corresponding to each polymorph: $v_{1}$ (symmetric stretching), $v_{2}$ (out-of-plane $\mathrm{CO}_{3}$ bending), $v_{3}$ (asymmetric $\mathrm{CO}_{3}$ stretching) and $v_{4}$ (in-plane $\mathrm{CO}_{3}$ bending). Only calcite is precipitated in pure water or in the presence of $\leq 25 \mathrm{vol} \%$ of ethanol. Hopper calcite crystals are precipitated when the ethanol content is less than $50 \mathrm{vol} \%$, while increasing the amount of ethanol to $>50 \mathrm{vol} \%$ considerably stabilizes an ACC precursor phase that eventually recrystallizes into vaterite. 


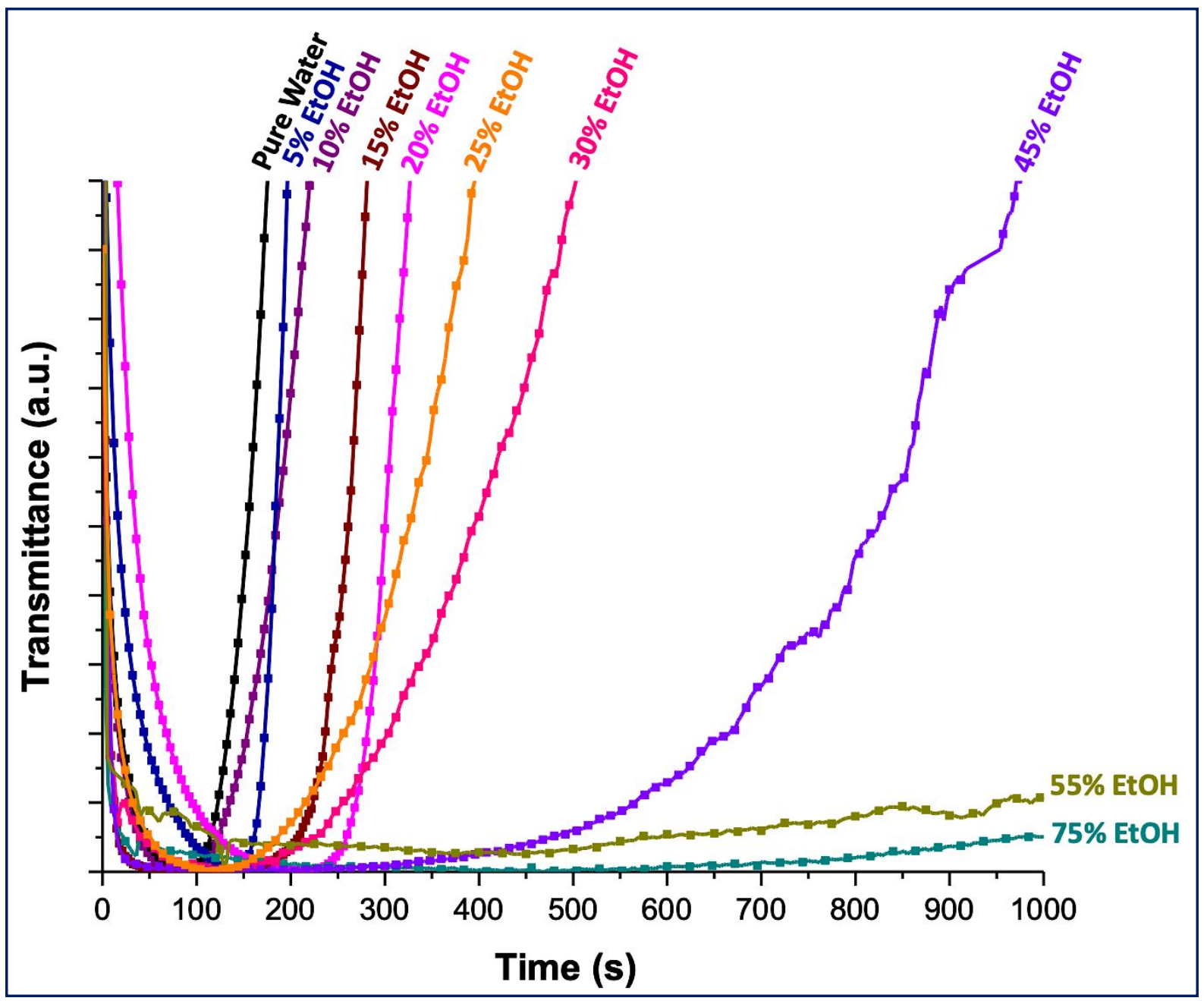

Figure S2. UV-Visible transmittance recovery as a function of time after mixing solutions of $20 \mathrm{mM}$ $\mathrm{CaCl}_{2}$ and $200 \mathrm{mM} \mathrm{NaHCO}$ in pure water and various ethanol/water ratios. Amounts of ethanol $\leq 30$ vol\% in solution do not significantly alter ACC precipitation and stability, where immediate precipitation of the amorphous phase is observed after mixing the ionic precursors. Dissolution starts after $100-250 \mathrm{sec}$ following mixing. In contrast, larger amounts of ethanol in solution ( $\geq 45 \mathrm{vol} \%)$ considerably enhance ACC stability, where transmittance recovery is significantly delayed. 


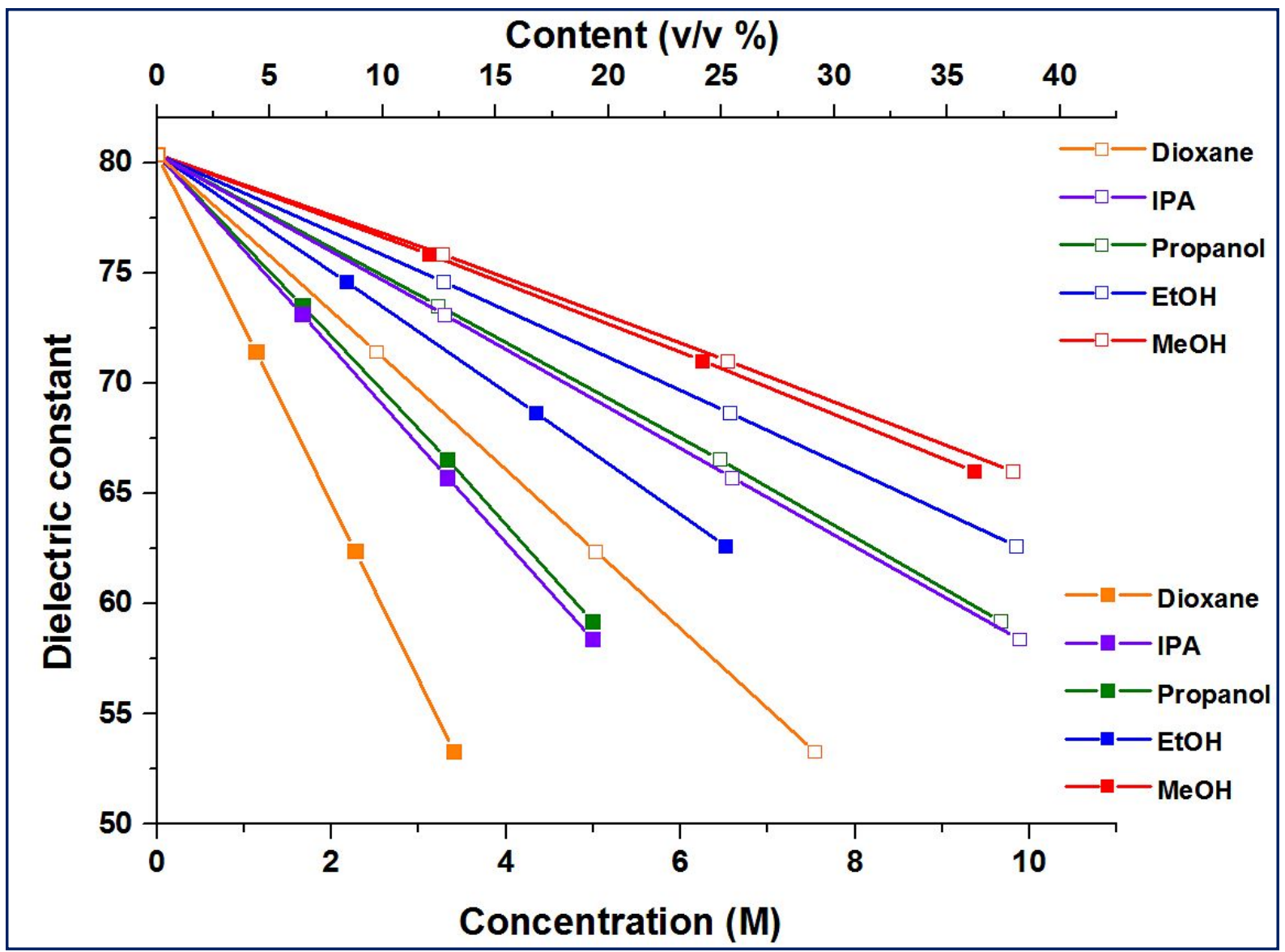

Figure S3. Graph showing the effect of the composition of various binary solvent mixtures on the dielectric constant of the solution at room temperature. The filled and empty squares correspond to the variation of the dielectric constant of the solution as a function of the co-solvent concentration and volume ratio, respectively. ${ }^{3,4}$ 

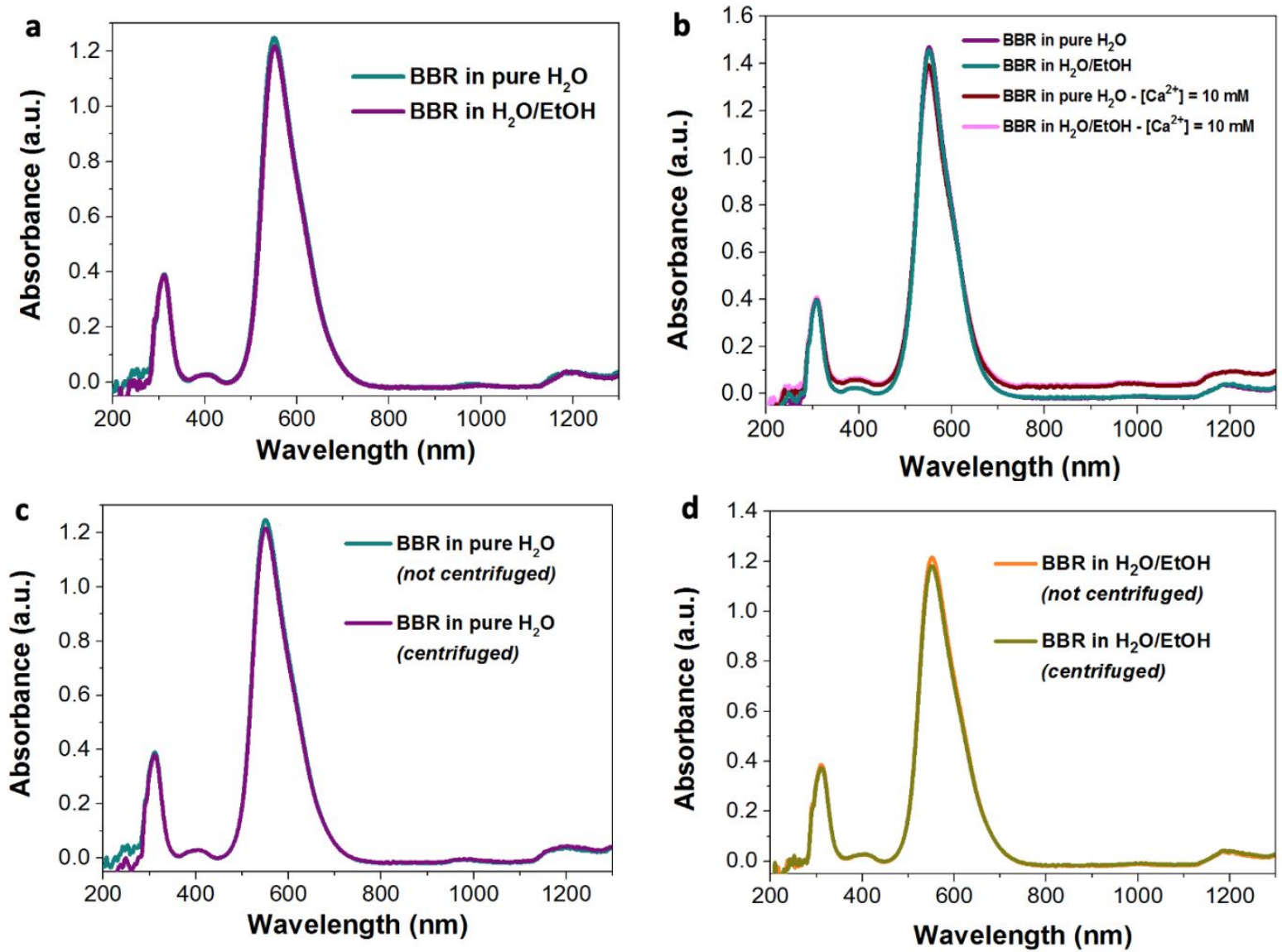

Figure S4. (a-b) UV-Visible-IR spectra of BBR solutions prepared in pure water and $20 \mathrm{vol} \%$ ethanol, in the absence and presence of $\mathrm{Ca}^{2+}$ ions. No significant changes in the spectra are recorded, which reveals that ethanol does not affect the structure of the dye. (b) The slight decrease in intensity of the absorbance peak at $550 \mathrm{~nm}$ is attributed to the complexation of $\mathrm{Ca}^{2+}$ ions with the dye. (c-d) UV-VisibleIR spectra of BBR solutions prepared in pure water and in the presence of $15 \mathrm{vol} \%$ ethanol before and after centrifugation. The minor decrease in intensity of the absorbance peak at $550 \mathrm{~nm}$ is attributed to the removal of dye aggregates in both solutions. 

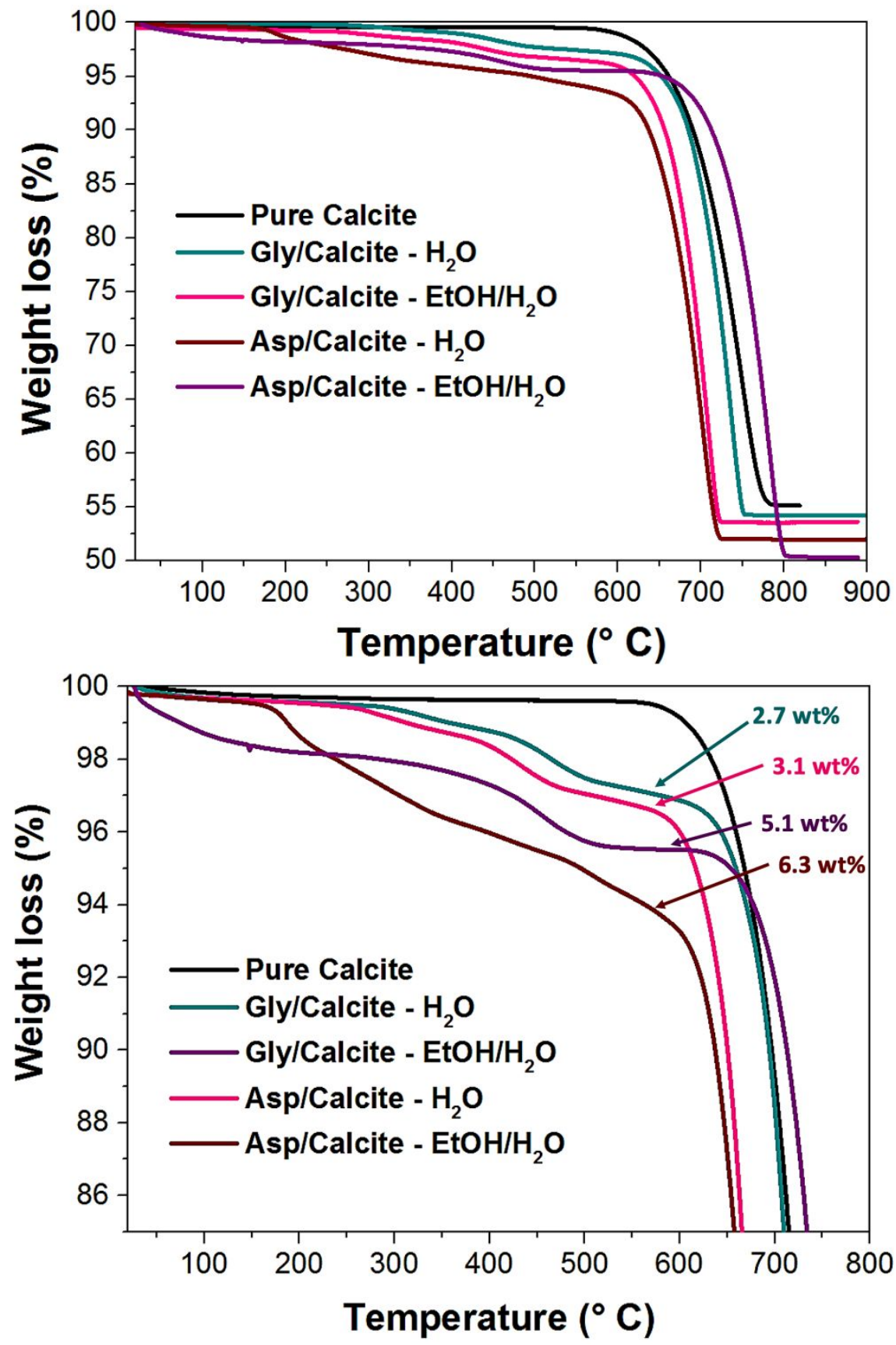

Figure S5. TGA of pure calcite (black), glycine/calcite (blue), aspartic acid/calcite (pink) grown in pure water and glycine/calcite (purple), aspartic acid/calcite (burgundy) grown in the presence of $15 \mathrm{vol} \%$ EtOH. The levels of occlusion of glycine (Gly) and aspartic acid (Asp) calcite are determined by the thermal degradations of the amino acids that induce weight losses when the composite crystals are annealed at temperatures below $600{ }^{\circ} \mathrm{C}$. Thermal decomposition of $\mathrm{CaCO}_{3}(\mathrm{~s}) \rightarrow \mathrm{CaO}(\mathrm{s})$ and $\mathrm{CO}_{2}(\mathrm{~g})$ takes place at temperature above $600{ }^{\circ} \mathrm{C}$. 

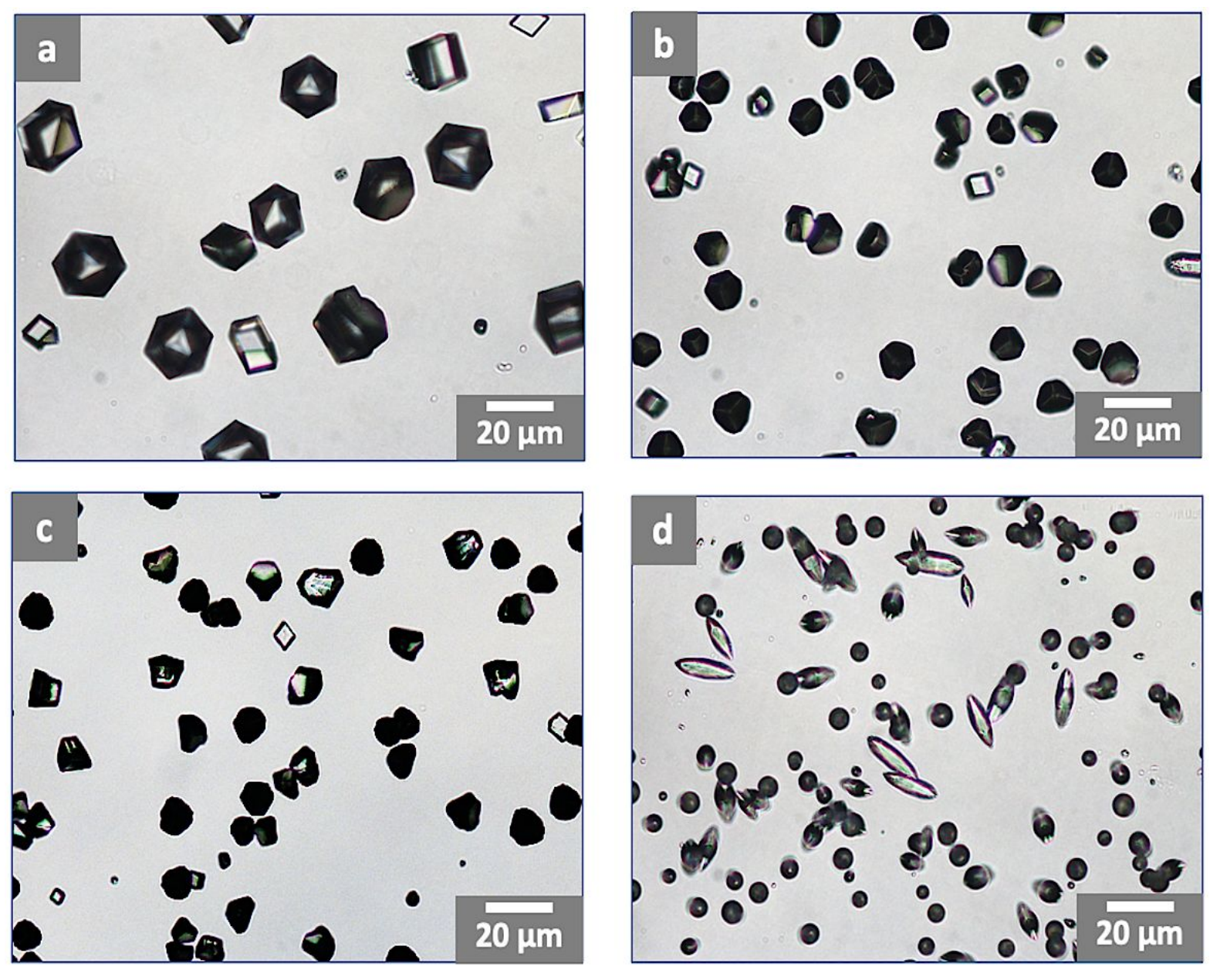

Figure S6. Optical images of calcite precipitated in the presence of $\left[\mathrm{Ca}^{2+}\right]=10 \mathrm{mM}$ and $\left[\mathrm{Mg}^{2+}\right]=5$ $\mathrm{mM}$, in (a) pure water and in the presence of (b) $5 \mathrm{vol} \%$, (c) $10 \mathrm{vol} \%$, and (d) $15 \mathrm{vol} \%$ of ethanol. The formation of gradually more elongated calcite crystals is indicative of the increased inclusion of magnesium in calcite. 


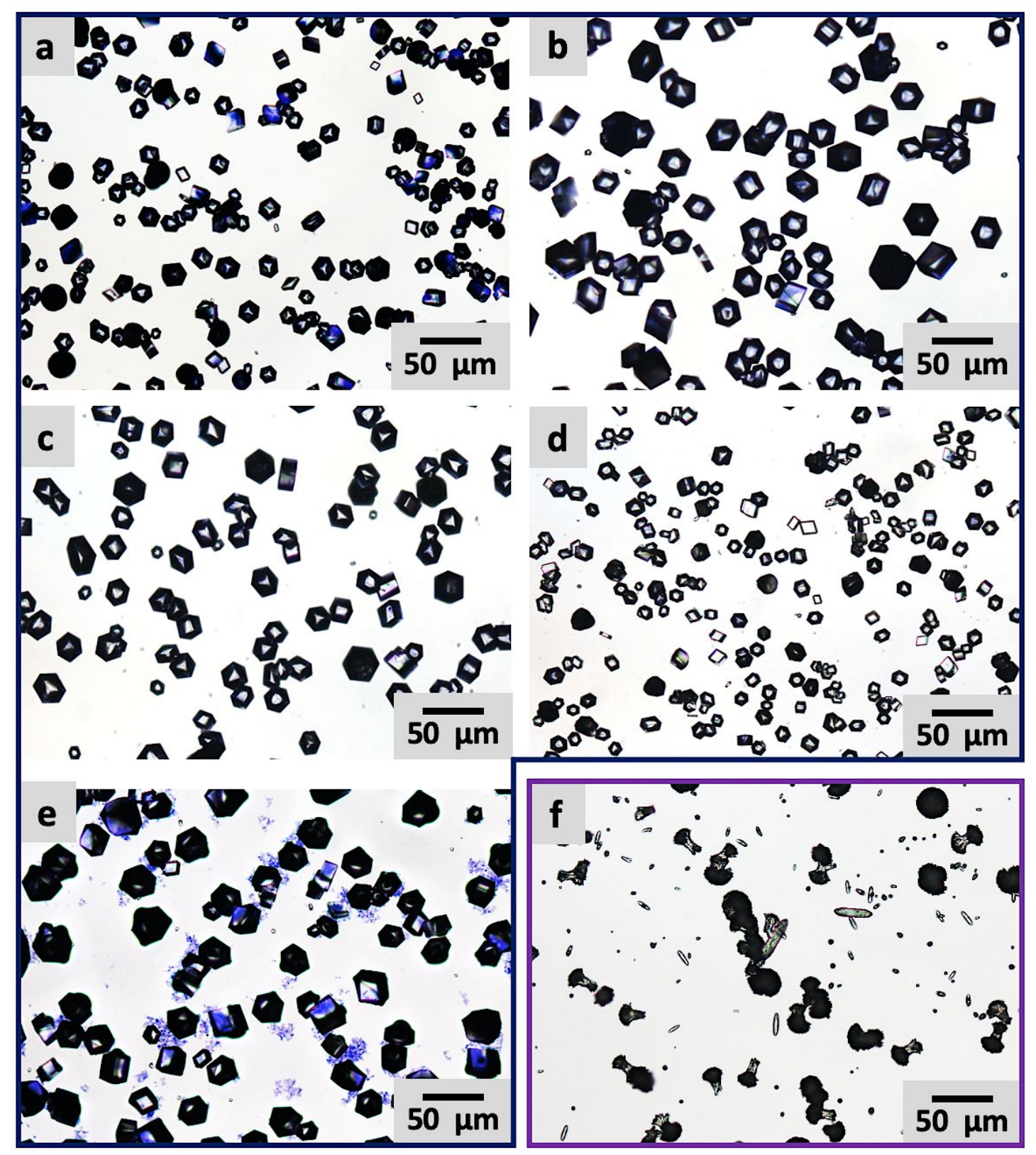

Figure S7. Calcite crystals precipitated in the presence of $[\mathrm{BBR}]=0.5 \mathrm{mM}$ and (a) $\left[\mathrm{Ca}^{2+}\right]=50 \mathrm{mM}$, (b) $\left[\mathrm{Ca}^{2+}\right]=100 \mathrm{mM}$, (c) $\left[\mathrm{Ca}^{2+}\right]=200 \mathrm{mM}$, (d) $\left[\mathrm{Ca}^{2+}\right]=500 \mathrm{mM}$. An increase of the supersaturation failed to enhance the morphology changes and dye incorporation, where only pale blue calcite rhombs precipitated. (e) Crystallization solution showing calcite crystals obtained from solutions containing $[\mathrm{BBR}]=0.2 \mathrm{mM}$ and $\left[\mathrm{Ca}^{2+}\right]=50 \mathrm{mM}$. Aggregates of the dye molecules are clearly visible in the crystallization solution. (f) Mixtures of elongated calcite and metastable aragonite polycrystals precipitated from $\left[\mathrm{Ca}^{2+}\right]=20 \mathrm{mM}$ and $\left[\mathrm{Mg}^{+}\right]=25 \mathrm{mM}$. 

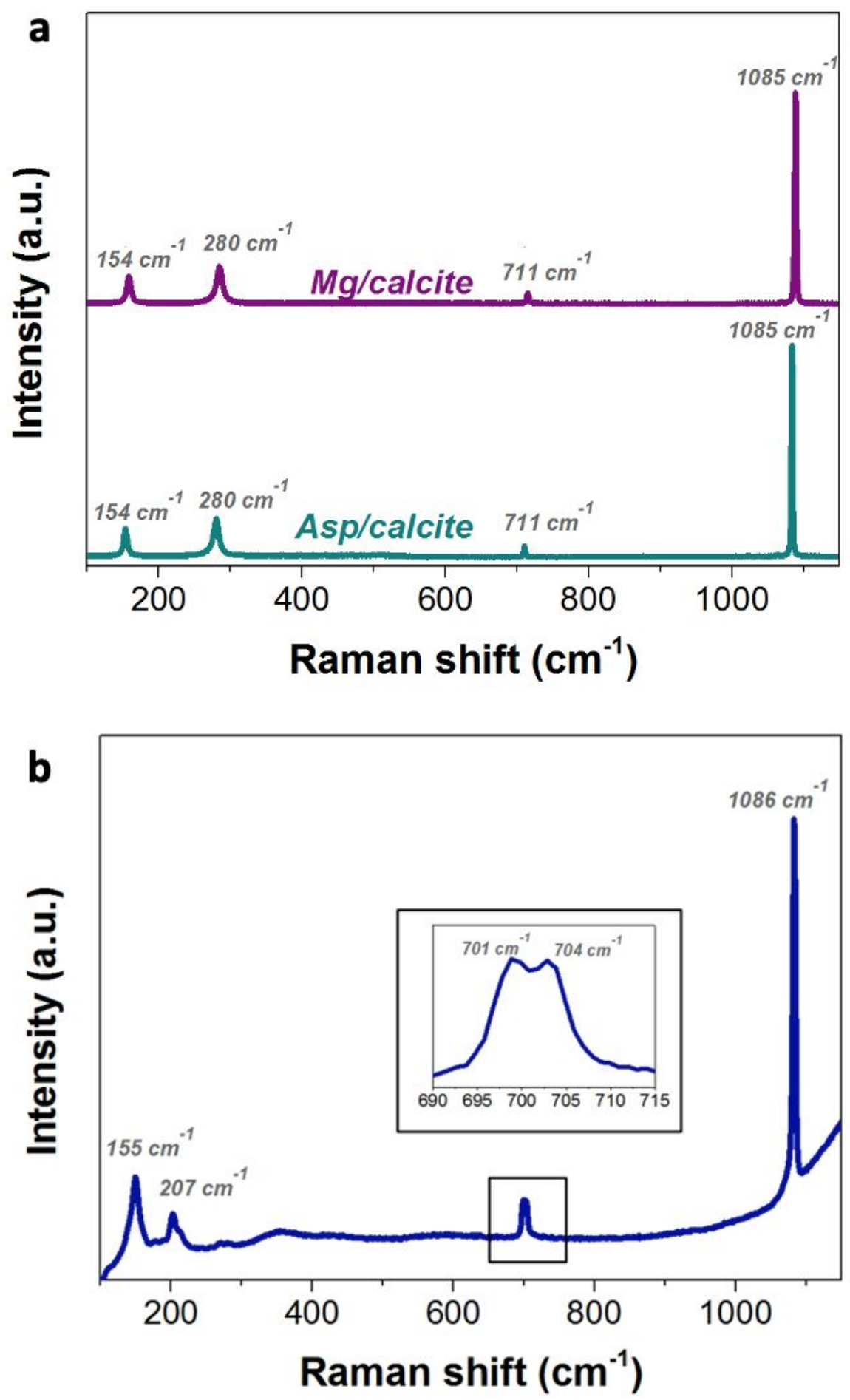

Figure S8. (a) Raman spectra of the $\mathrm{CaCO}_{3}$ crystals precipitated in the presence of [aspartic acid] $=75$ $\mathrm{mM}$ and $\left[\mathrm{Ca}^{2+}\right]=20 \mathrm{mM}$ (cyan), and $\left[\mathrm{Mg}^{2+}\right]=20 \mathrm{mM}$ and $\left[\mathrm{Ca}^{2+}\right]=10 \mathrm{mM}$ (purple), showing the characteristic peaks of calcite. (b) Raman spectra of aragonite crystals precipitated in the presence of $\left[\mathrm{Mg}^{2+}\right]=50 \mathrm{mM}$ and $\left[\mathrm{Ca}^{2+}\right]=10 \mathrm{mM}$. 

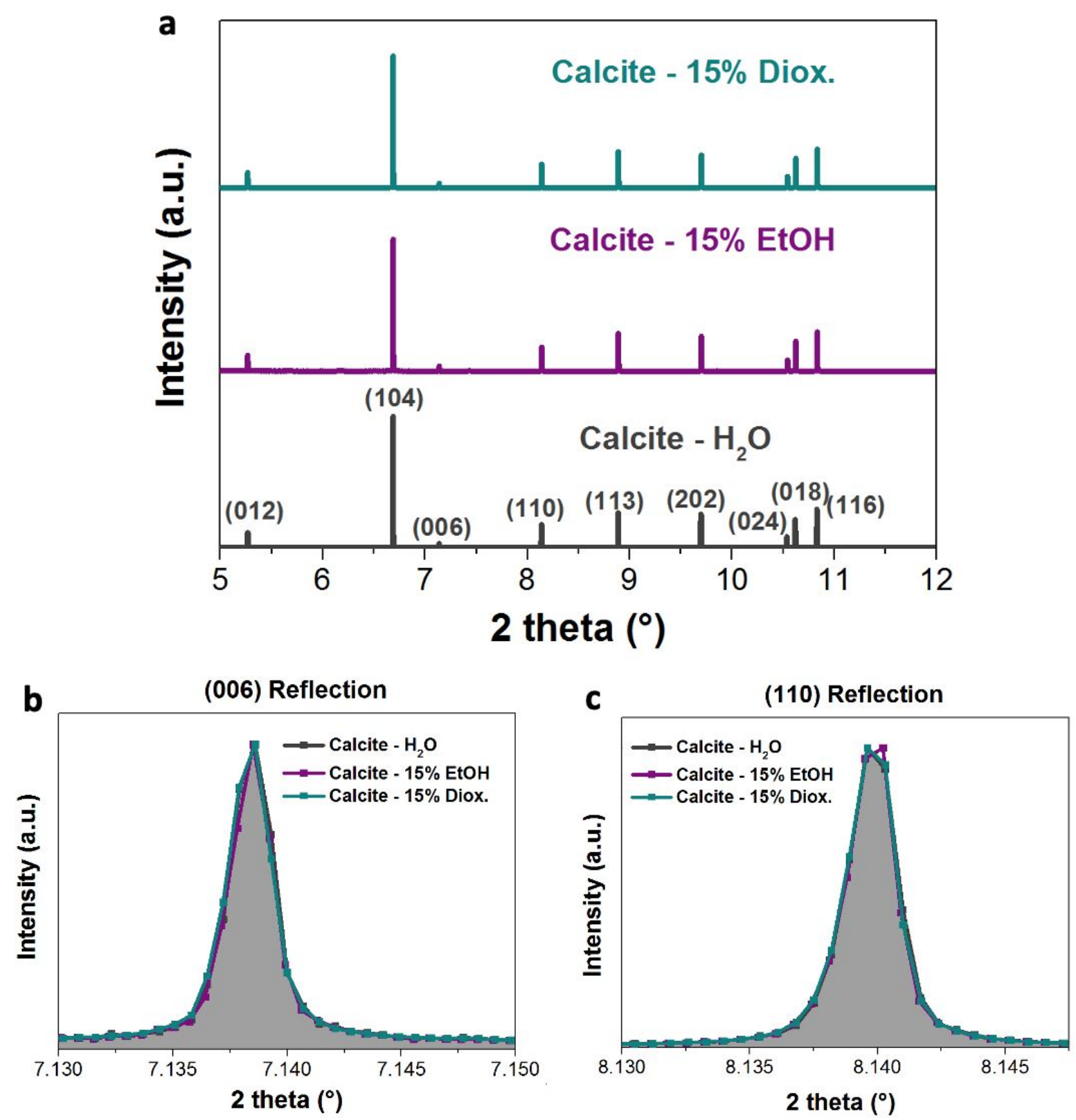

Figure S9. (a) HR-PXRD diffractograms $(\lambda=0.35449587 \AA)$ of calcite crystals grown in pure water (dark grey), and in the presence of 15 vol\% of ethanol (purple) and dioxane (cyan). (b) HR-PXRD patterns of the (006) and (110) reflections of calcite grown in various solvent mixtures, showing no change in the position, shape and broadening of the peaks. This shows that organic solvents $(<15 \mathrm{vol} \%)$ do not affect the microstructure of the calcite crystals. 

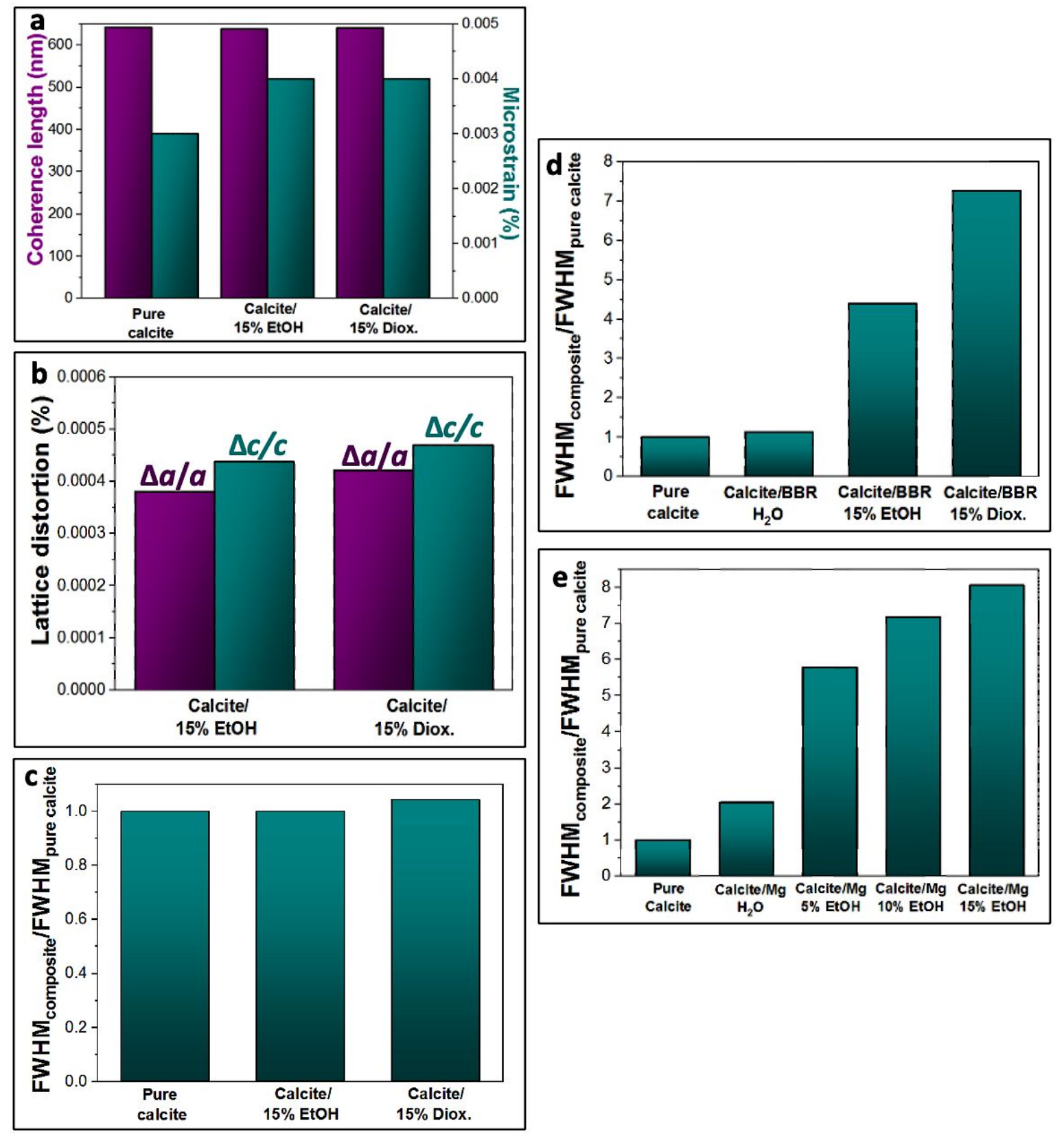

Figure S10. (a) Coherence lengths and microstrain fluctuations, (b) lattice distortions along the $a$-axis and $c$-axis and (c) full-width at half maximum (FWHM) of calcite grown in pure water, and in the presence of 15 vol\% of ethanol and dioxane in the mineralization solution. (d) FWHM of pure calcite, and BBR/calcite and (e) $\mathrm{Mg} /$ calcite composites, grown in pure water and ethanol/water mixtures. 
a

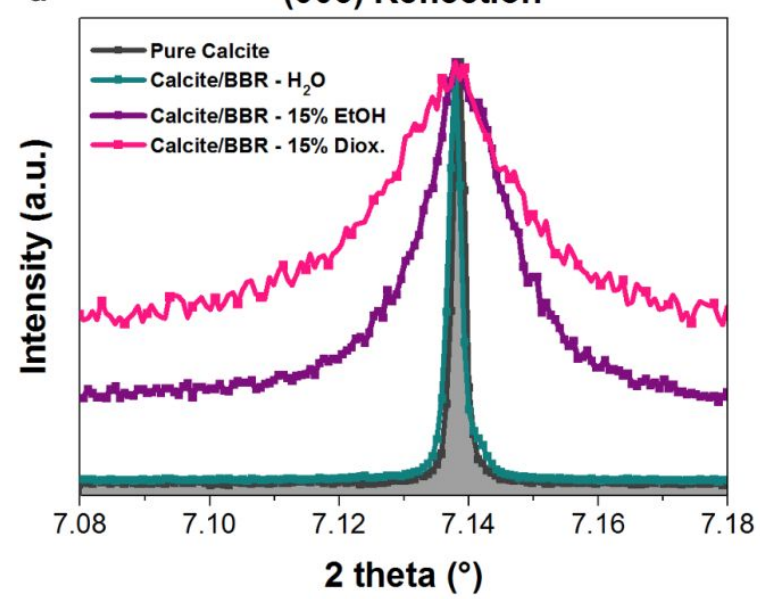

b

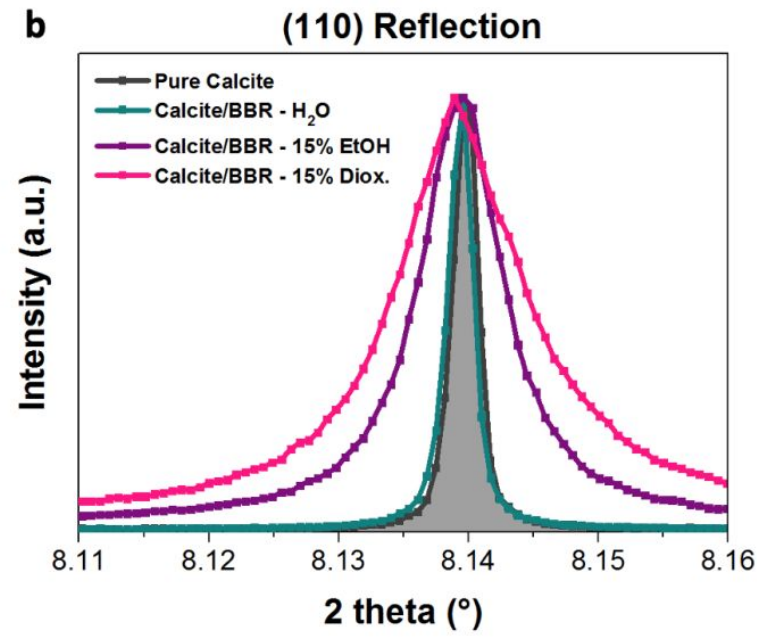

Figure S11. (a-b) HR-PXRD diffractograms $(\lambda=0.35449587 \AA)$ of the (006) and (110) reflections of pure calcite crystals (dark grey), and BBR/calcite composites grown in pure water (cyan), and in the presence of $15 \mathrm{vol} \%$ ethanol (purple) and in dioxane (pink). The high levels of incorporation of dye in calcite achieved in solvent mixtures mainly generate a significant broadening of the diffraction peaks, while only minor peak shifts are recorded. 


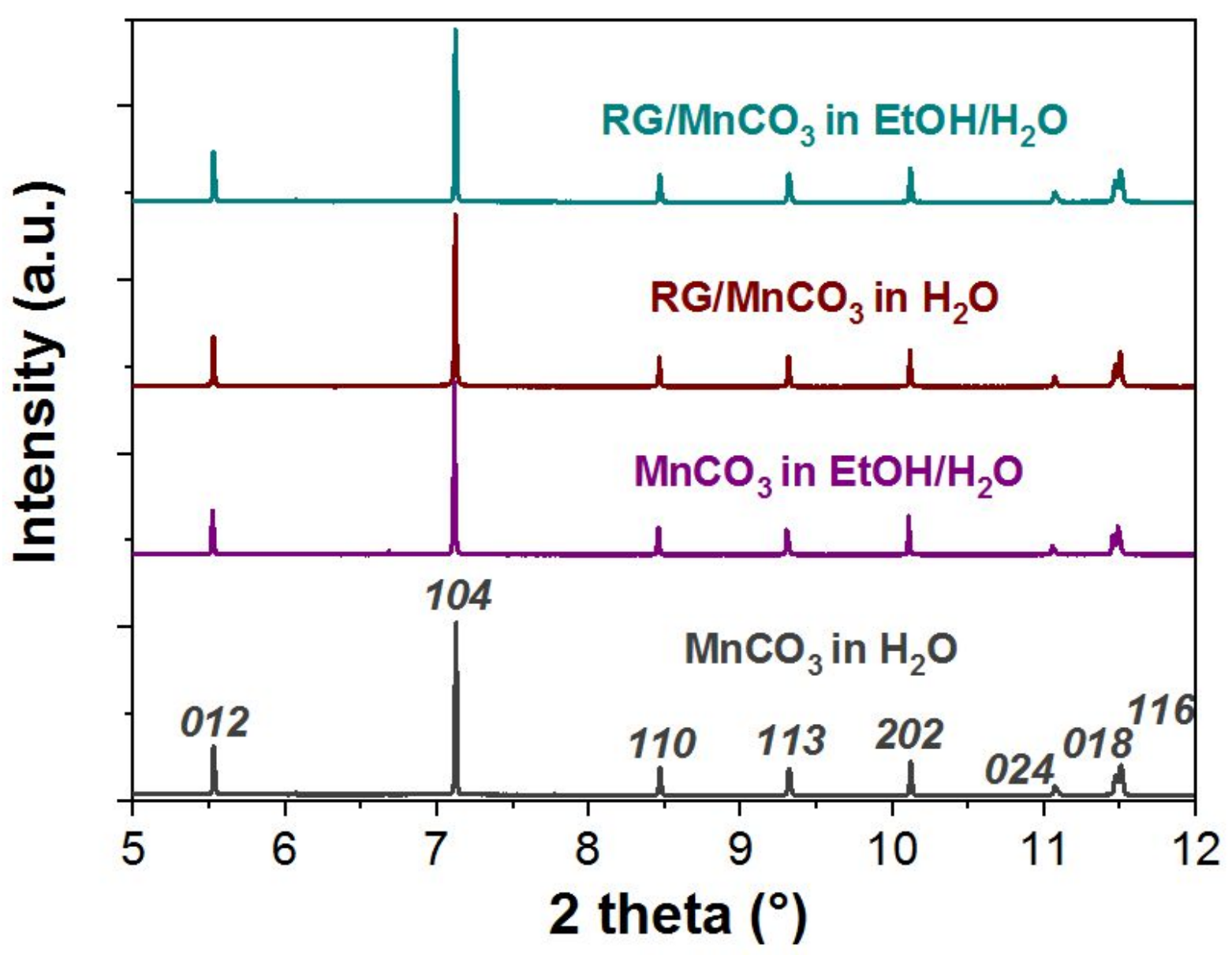

Figure S12. HR-PXRD diffractograms $(\lambda=0.35449587 \AA)$ of pure $\mathrm{MnCO}_{3}$ crystals grown in pure water (dark grey), pure $\mathrm{MnCO}_{3}$ crystals grown in the presence of $10 \mathrm{vol} \%$ of ethanol (purple), Reactive Green/ $\mathrm{MnCO}_{3}$ composites $\left(\mathrm{RG} / \mathrm{MnCO}_{3}\right)$ precipitated in pure water (dark red), and Reactive Green/ $\mathrm{MnCO}_{3}$ composites $\left(\mathrm{RG} / \mathrm{MnCO}_{3}\right)$ precipitated in the presence of $10 \mathrm{vol} \%$ of ethanol (light blue). In all cases the diffraction peaks correspond to rhodochrosite. 


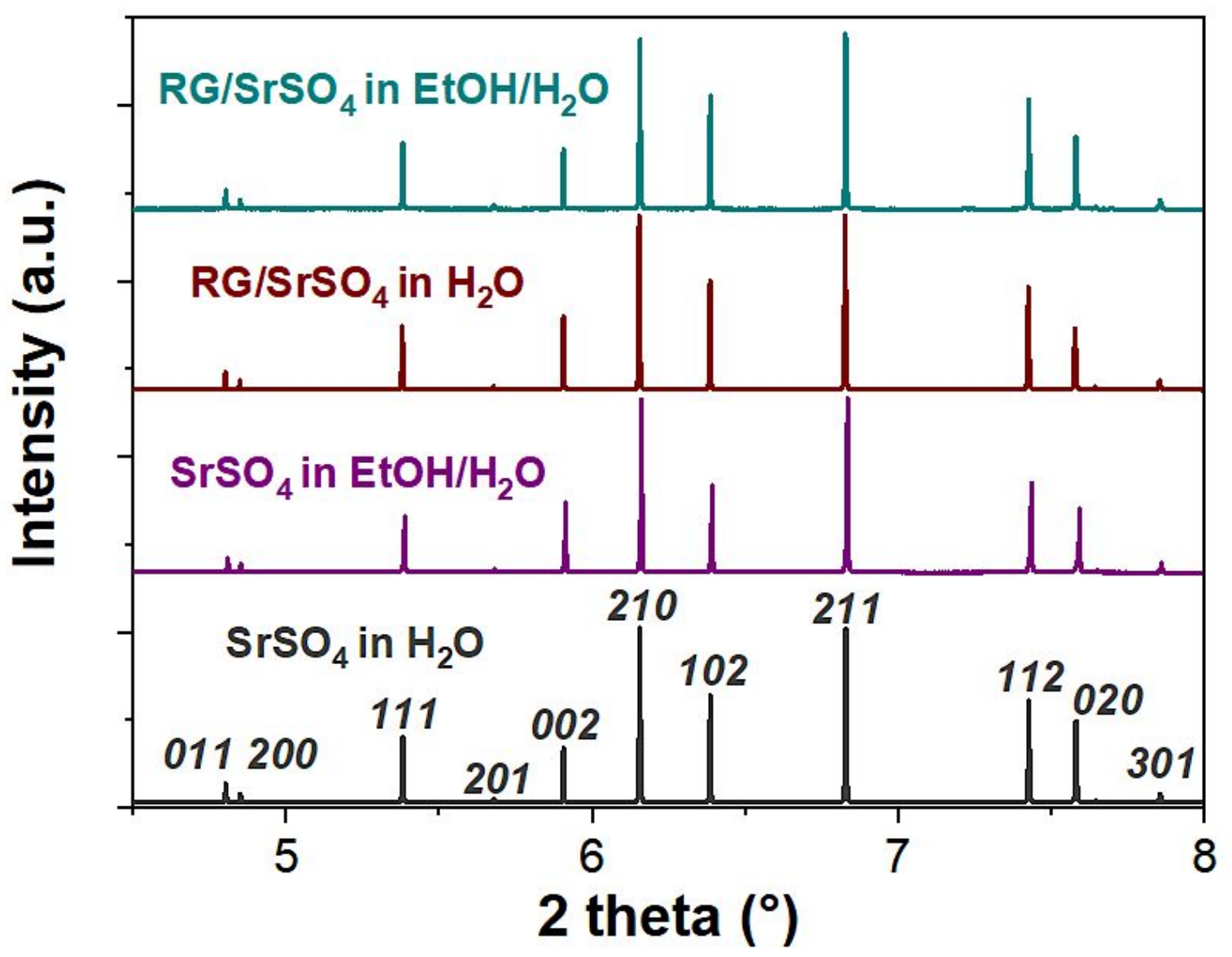

Figure S13. HR-PXRD diffractograms $(\lambda=0.35449587 \AA)$ of pure $\mathrm{SrSO}_{4}$ crystals grown in pure water (dark grey), pure $\mathrm{SrSO}_{4}$ crystals grown in the presence of $10 \mathrm{vol} \%$ of ethanol (purple), Reactive Green/ $/ \mathrm{SrSO}_{4}$ composites ( $\mathrm{RG} / \mathrm{SrSO}_{4}$ ) precipitated in pure water (dark red), and Reactive $\mathrm{Green} / \mathrm{SrSO}_{4}$ composites $\left(\mathrm{RG} / \mathrm{SrSO}_{4}\right)$ precipitated in the presence of $10 \mathrm{vol} \%$ of ethanol (light blue). In all cases the diffraction peaks correspond to celestine. 

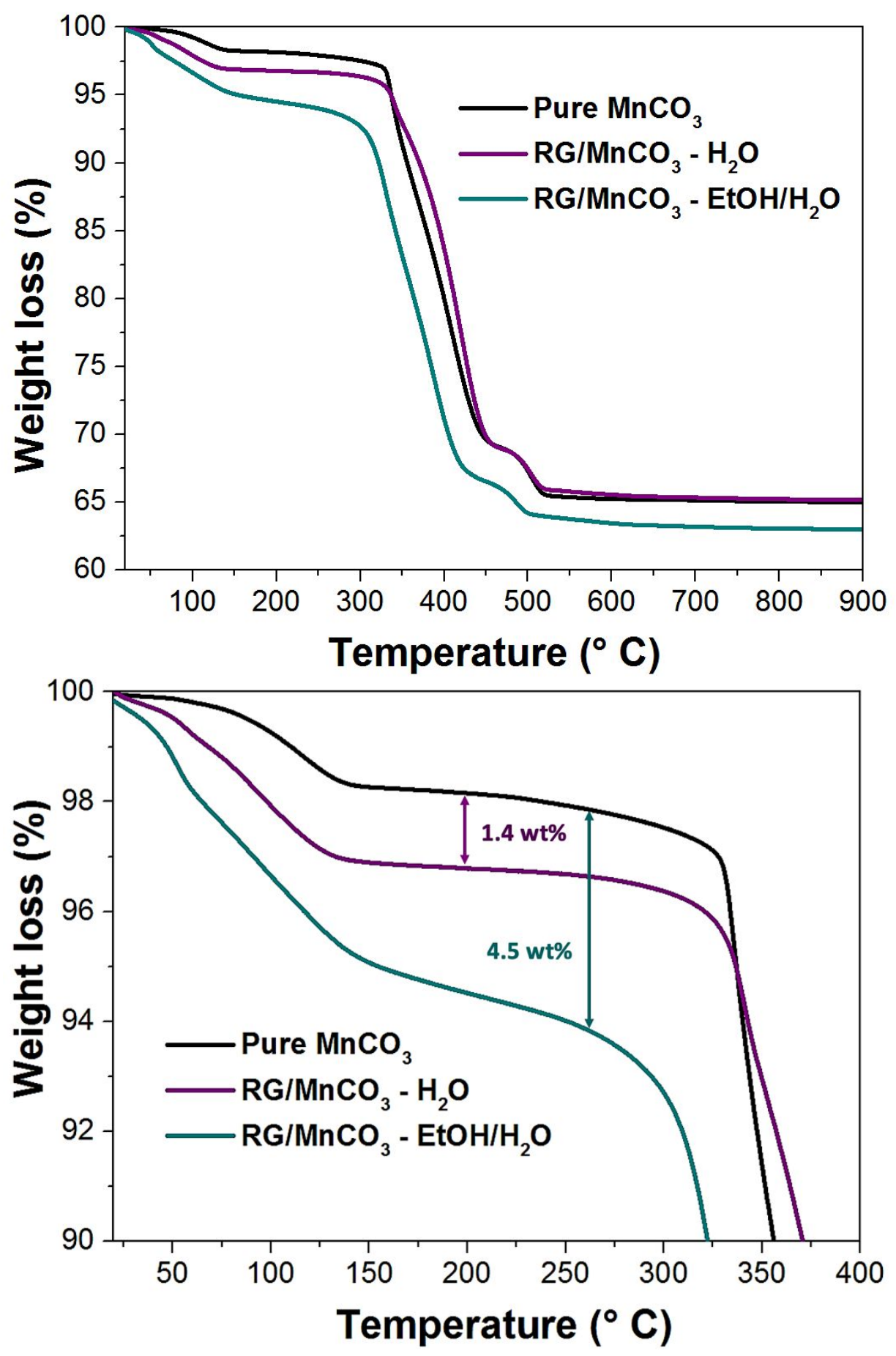

Figure S14. TGA of pure $\mathrm{MnCO}_{3}$ (black), Reactive $\mathrm{Green} / \mathrm{MnCO}_{3}\left(\mathrm{RG} / \mathrm{MnCO}_{3}-\right.$ purple) grown in pure water and Reactive Green $/ \mathrm{MnCO}_{3}\left(\mathrm{RG} / \mathrm{MnCO}_{3}-\right.$ blue $)$ grown in the presence of $10 \mathrm{vol} \%$ of ethanol in solution. The levels of dye incorporation in rhodochrosite are determined by the weight losses occurring below $300{ }^{\circ} \mathrm{C}$. Higher annealing temperatures form manganese oxide. 


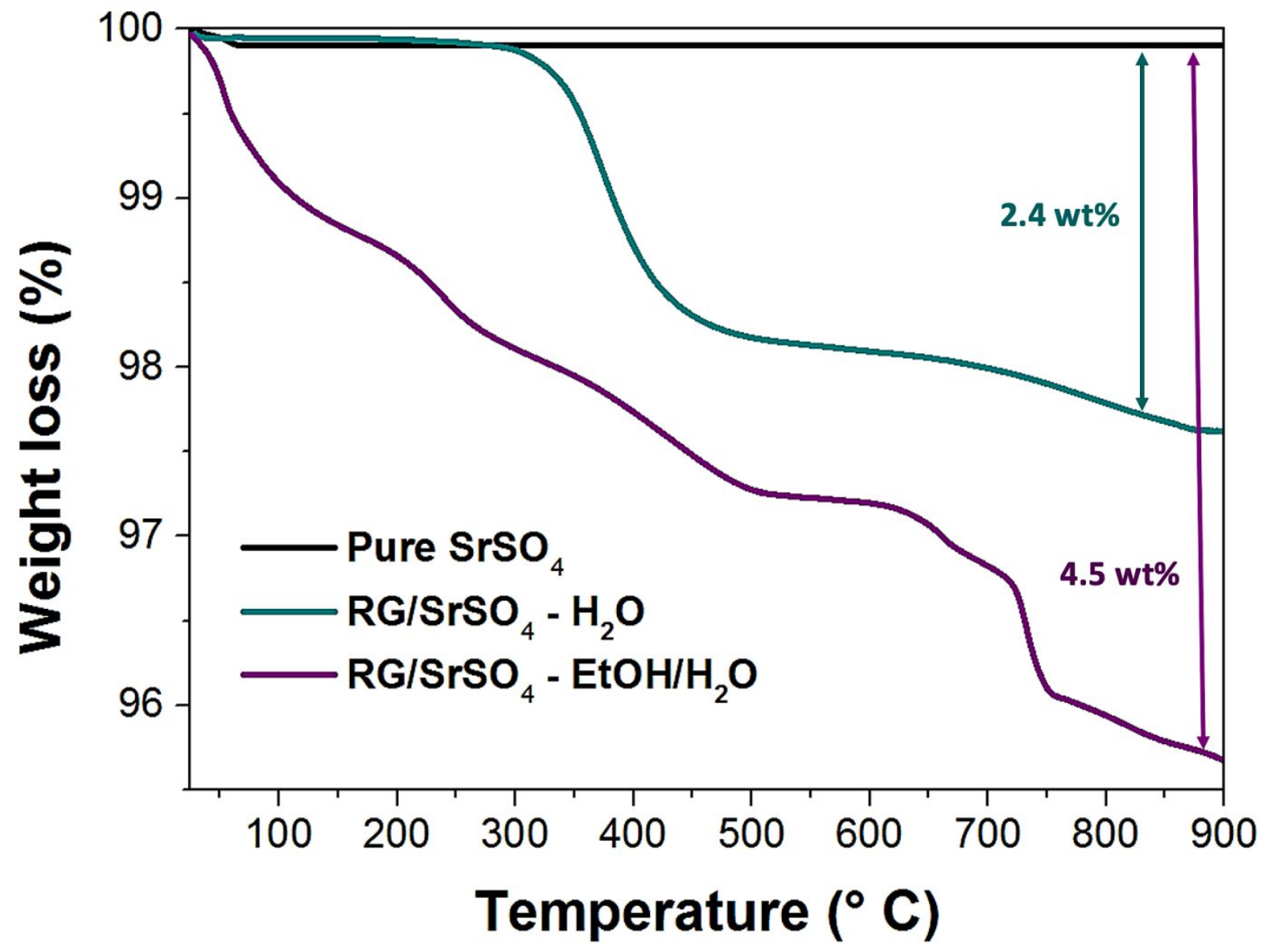

Figure S15. TGA of pure $\mathrm{SrSO}_{4}$ (black), Reactive Green/ $\mathrm{SrSO}_{4}\left(\mathrm{RG} / \mathrm{SrSO}_{4}-\right.$ blue) grown in pure water and Reactive Green/ $\mathrm{SrSO}_{4}\left(\mathrm{RG} / \mathrm{SrSO}_{4}-\right.$ purple $)$ grown in the presence of $10 \mathrm{vol} \%$ of ethanol in solution. The levels of dye incorporation in celestine are determined by the weight losses recorded between room temperature and $900{ }^{\circ} \mathrm{C}$. No weight loss was recorded for pure $\mathrm{SrSO}_{4}$. 


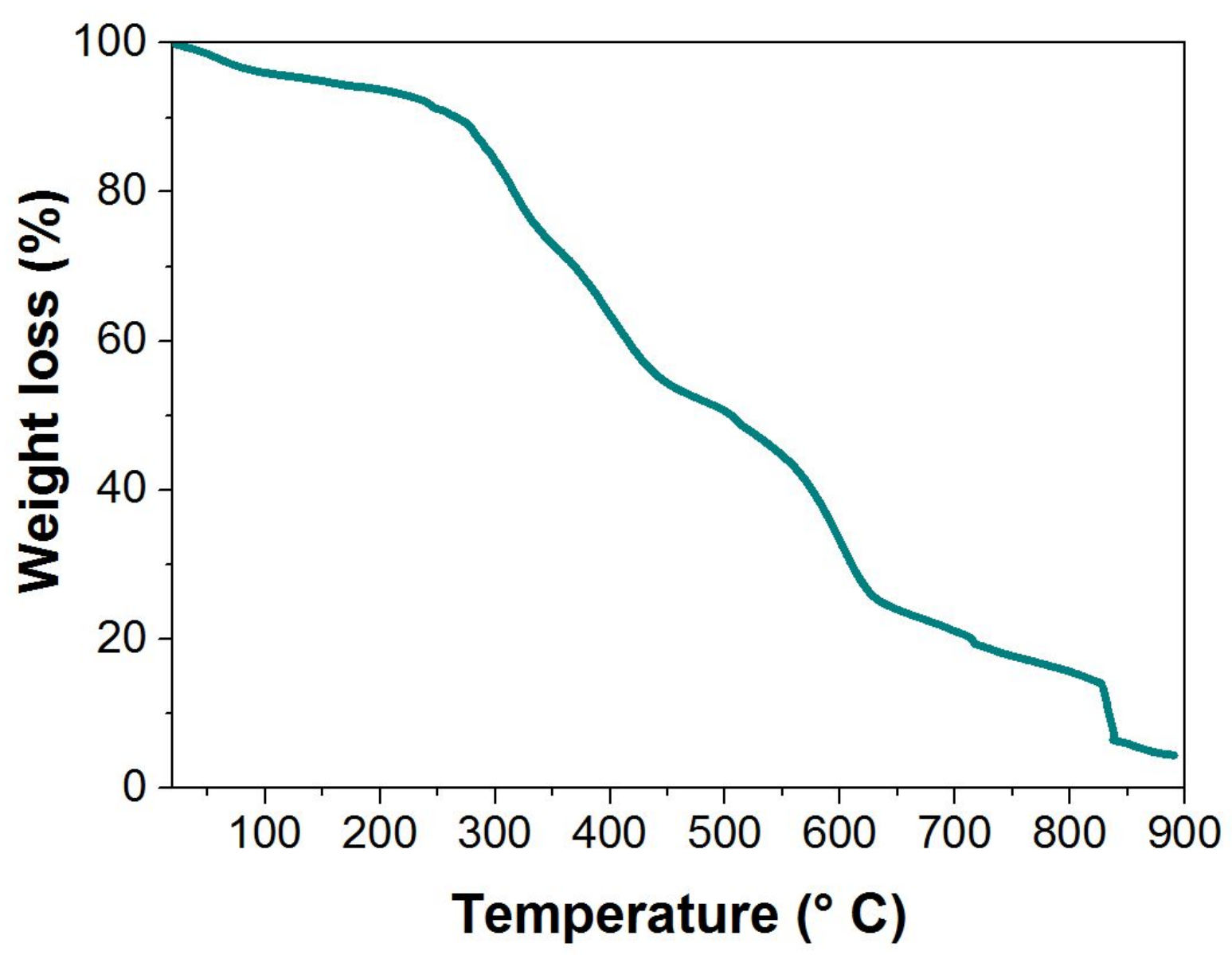

Figure S16. TGA of Reactive Green dye alone showing that $<5 \mathrm{wt} \%$ of dye remains in the crucible after annealing at $900{ }^{\circ} \mathrm{C}$. 


\section{SUPPORTING INFORMATION}

Table S1. Structures and colors of the dye molecules used as additives.

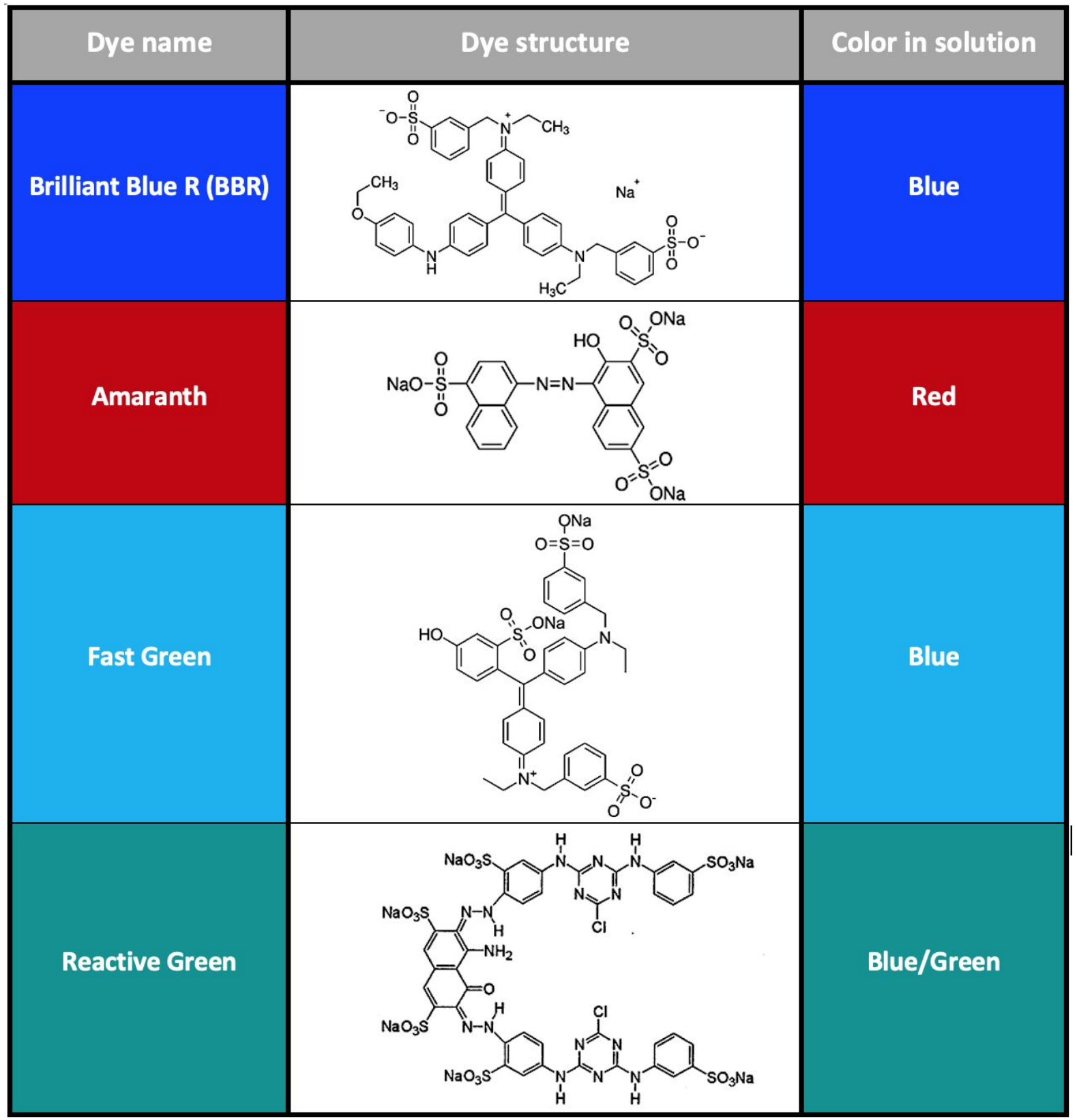




\section{SUPPORTING INFORMATION}

\section{REFERENCES}

(1) Ihli, J.; Bots, P.; Kulak, A.; Benning, L. G.; Meldrum, F. C., Elucidating Mechanisms of Diffusion-Based Calcium Carbonate Synthesis Leads to Controlled Mesocrystal Formation. Adv. Funct. Mater. 2013, 23, (15), 1965-1973.

(2) Penkman, K. E.; Kaufman, D. S.; Maddy, D.; Collins, M. J., Closed-system behaviour of the intra-crystalline fraction of amino acids in mollusc shells. Quat. Geochronol. 2008, 3, (1-2), 2-25.

(3) Akerlof, G.; Short, O. A., The Dielectric Constant of Dioxane-Water Mixtures between 0 and $80^{\circ}$. J. Am. Chem. Soc. 1936, 58, (7), 1241-1243.

(4) Akerlof, G., Dielectric constants of some organic solvent-water mixtures at various temperatures. J. Am. Chem. Soc. 1932, 54, (11), 4125-4139. 